\title{
Impact of Women Empowerment on Infant Mortality Rate - Spatial Lag and Error Regression Model
}

\author{
Kanwal Preet K. Gill, Priyanka Devgun, and Amanpreet Kaur
}

\section{ABSTRACT}

Background: Despite significant progress in recent decade, the burden of infant mortality in India remains high. As women is the main caregiver to the infant, women empowerment may be the important determinant of infant mortality rate which has received little attention. Therefore, the current study was planned to study the impact of women empowerment on infant mortality and to find the best fit regression model to predict infant mortality rate in various states of India.

Methods: The National Family Health Survey (NFHS) 2015-16 data was used and infant mortality rate in various states and union territories of India was mapped. Regression analysis was performed with infant mortality rate as the dependent variable. The exploratory variables (Percentages) used for women empowerment were the literacy among women, women who opted for institutional delivery, women owning a house and/or land (alone or jointly with others), women having a bank or saving account and women having mobile phone that they themselves used. Ordinary Least Square Regression and spatial lag and error regression models were applied. Infant mortality rates predicted by using the best fit model were mapped.

Results: Institutional delivery, owning a bank account and availability of personal mobile phone showed statistically significant inverse relation with infant mortality rate. Out of three regression models, spatial lag regression model was found to be the best fit model to predict infant mortality rate. The northern and eastern states were predicted to have highest infant mortality rate.

Conclusion: As northern and eastern states were predicted to have highest infant mortality rate, further studies at individual level may be planned to find out the factors in these regions.

Keywords: Infant mortality, spatial, lag and error, regression models.
Published Online: December 15, 2020 ISSN: 2593-8339

DOI: $10.24018 /$ ejmed.2020.2.6.601

Kanwal Preet K. Gill*

Sri Guru Ram Das Institute of Medical Sciences \& Research, Amritsar $(\mathrm{Pb})$, India.

(e-mail: kpreet224@gmail.com)

Priyanka Devgun

Sri Guru Ram Das Institute of Medical Sciences \& Research, Amritsar $(\mathrm{Pb})$, India

(e-mail: pd1843@gmail.com)

Amanpreet Kaur

Sri Guru Ram Das Institute of Medical Sciences \& Research, Amritsar $(\mathrm{Pb})$, India.

(e-mail: divupari138@gmail.com)

*Corresponding Author

\section{INTRODUCTION}

Infant mortality rate is one of the important indicators to assess the health and standard of living of a country. Despite significant progress in recent decade, the burden of infant mortality in India still remains high. As per United Nation's estimates, there were 721,000 infant deaths in India in 2018 which accounts for 1975 deaths per day on an average [1]. India, with infant mortality rate of 28.3 per thousand live births in 2019 is not among the countries with low infant mortality rates [2]. Also, there is a widespread geographical variation in infant mortality rate among various states. Therefore, additional efforts are required to remove these inequities and to address every child's right to survival [3]. According to World Health Organization, the presence of trained health professional at the time of delivery plays an important role to decrease the child mortality [4]. For this reason, India has started a number of health programmes like Janani Suraksha Yojna, Janani Shishu Suraksha Karyakaram, to promote institutional delivery. As women is the main caregiver to the infant, women empowerment may be the important determinant of utilization of available resources which has received a little attention. National Family Health Survey has included a number of indicators related to women empowerment [5]. Hence, the current study was planned to observe the impact of these indicators of women empowerment on infant mortality rate. According to Tobler's first law of geography, everything is usually related to all else, but those which are near to each other are more related than the distant ones [6]. In accordance with Tobler's first law of geography, Silva et al has also proved that neighboring regions show similar infant mortality rates than the distant ones which is termed as spatial dependence [7]. Therefore, to adjust for this spatial dependence, the spatial statistical methods must be incorporated to analyze the infant mortality rate. With this aim, spatial lag and error regression models were built to predict infant mortality rates in different states of India. 


\section{METHODS}

India is geographically divided into 28 states and 8 union territories. Infant mortality rate was analyzed in different states and union territories of India. The National Family Health Survey (NFHS) 2015-16 data was used. The data was downloaded from Demographic Health Survey (DHS) Program. The permission to use this data was sought dated $27^{\text {th }}$ October 2020 . As this is a study with aggregate data, the ethical permission was not required.

To start with, the choropleth map was made in Arcmap to observe infant mortality in different states \& union territories of India. To observe clustering of states with similar infant mortality rate, Global and Local spatial autocorrelation analysis was performed in GeoDa. Global autocorrelation gives us the idea about the presence of of clusters, but local autocorrelation tells us the geographical areas where clustering is present.

Modelling: Infant mortality rate was taken as a dependent variable. The exploratory variables (Percentages) used were the literacy among women, women who opted for institutional delivery, women who participated in household decision, women who worked in the last 12 months and were paid in cash, women owning a house and/or land (alone or jointly with others), women having a bank or saving account and women having a mobile phone that they themselves used.

The ordinary least square regression analysis was performed with different variables. To improve the performance of model and to remove collinearity, work done in the past 12 months paid in cash was dropped from the analysis. The ordinary least square analysis was performed with the remaining exploratory variables. The results obtained were analyzed. Jarque bera test was performed to confirm that the results are not biased. Heteroskedasticity was ruled out by Breusch-Pagan test and Koenker-Bassett test.

To adjust for spatial dependence, Spatial Lag and Error regression analysis in GeoDa was performed by using queen intiguity weights. The queen intiguity weight considers all neighbours sharing boundaries as well as corners in the analysis. The results of three models were compared by using $\mathrm{R}$ square value. The model with highest value of $\mathrm{R}$ square was considered the best. The predicted values of infant mortality rates by the best fit model in different states were mapped.

\section{RESULTS AND DisCUSSION}

Infant mortality rate in all states of India was mapped (Fig. 1).

It was observed that there was a wide variation of infant mortality rate in different states ranging from 7/1000 live births to 48/1000 live births. A large number of eastern and northern states depicted high infant mortality rates whereas the figure was found to be on the lower side in southern states.

The global Moran I (Fig. 2) analysis was performed to observe autocorrelation of infant mortality rate among various states.

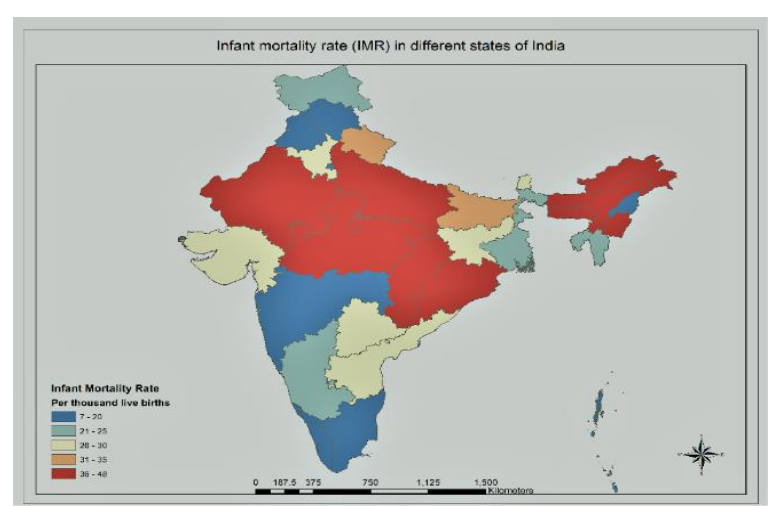

Fig. 1. A map showing infant mortality rate in various states of India.

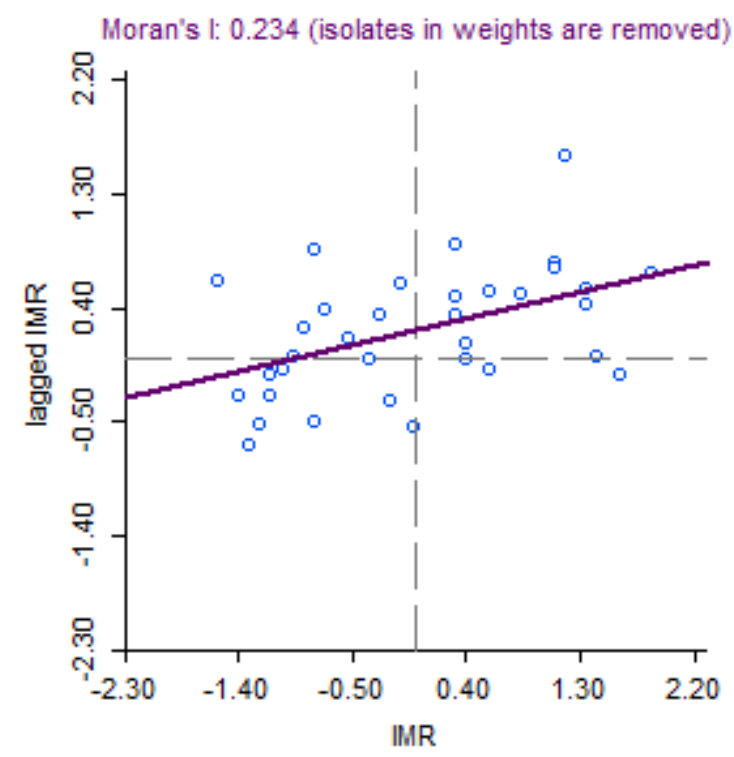

Fig. 2. Moran's scatter diagram for Infant Mortality Rate (IMR).

Moran's Index was found to be 0.23 with $p$ value of 0.029. It shows that there is a positive spatial dependence with states with high infant mortality rates surrounded by similar states. Positive sign of Moran's Index, like Pearson correlation coefficient, depicts positive spatial correlation (clustering of areas with similar attribute values), negative sign depicts negative correlation and 0 depicts no correlation. It also quantifies the similarity of an outcome variable among areas that are defined as spatially dependent.

Local spatial autocorrelation was performed. Local indicator of spatial association (LISA) showed significant clustering in some areas with high infant mortality rate (Fig. 3 (a) and the results were statistically significant (Fig. 3 (b).

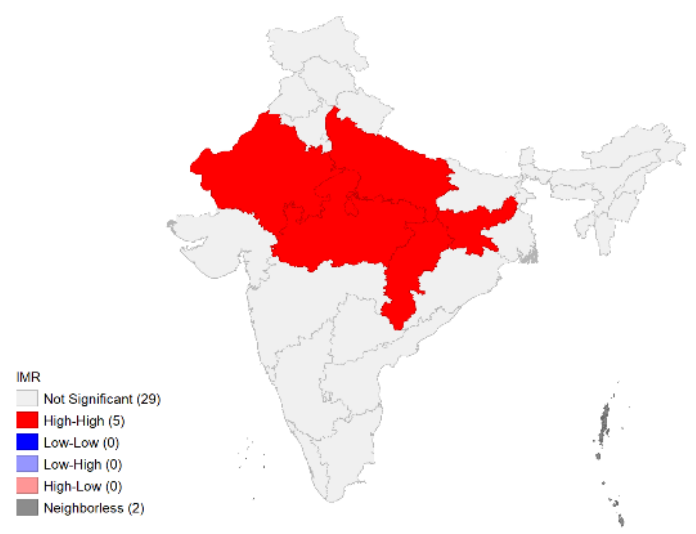

Fig. 3 (a). LISA cluster map. 


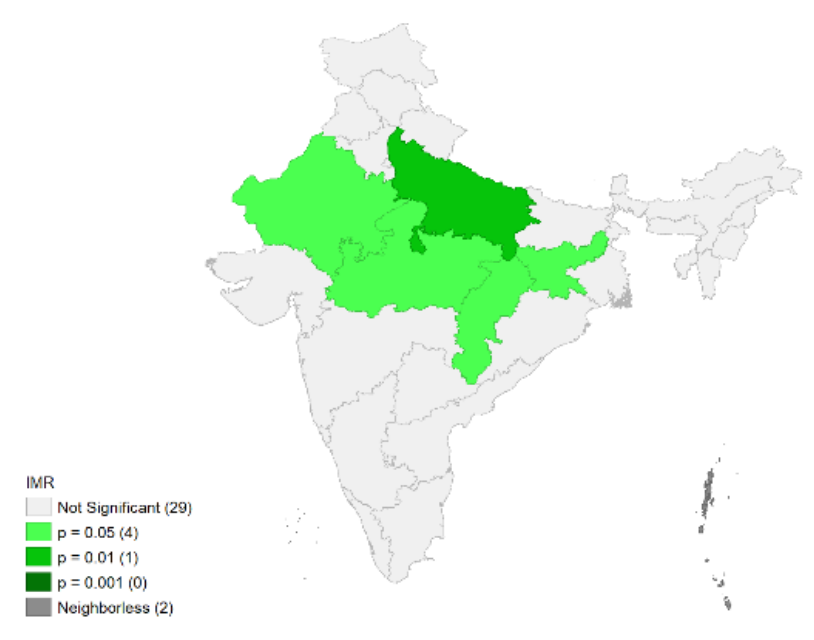

Fig. 3 (b). LISA significance map.

The ordinary least square (OLS) regression model was applied, and the results were observed. To improve the performance of model and to remove collinearity, the variable with percentage of women on paid work for the last 12 months was dropped from further analysis. The resultant OLS regression analysis results are shown in Table I.

TABLE I: THE RESULTS OF ORDINARY LEAST SQUARE REGRESSION ANALYSIS FOR INFANT MORTALITY RATE (OLS)

\begin{tabular}{ccccc}
\multicolumn{5}{c}{ ANALYSIS FOR INFANT MORTALITY RATE (OLS) } \\
\hline Variable & Coefficient & $\begin{array}{c}\text { Standard } \\
\text { Error }\end{array}$ & t-statistics & Probability \\
\hline $\begin{array}{c}\text { Constant } \\
\text { Women }\end{array}$ & 70.62 & 24.67 & 4.03 & $0.008^{*}$ \\
$\begin{array}{c}\text { Literacy } \\
\text { Rate }\end{array}$ & -0.11 & 0.20 & -0.56 & 0.58 \\
$\begin{array}{c}\text { Institutional } \\
\text { delivery }\end{array}$ & -0.32 & 0.12 & -2.68 & $0.01^{*}$ \\
$\begin{array}{c}\text { Participation } \\
\text { in decision } \\
\text { Own land or } \\
\text { house }\end{array}$ & -0.13 & 0.29 & -0.43 & 0.66 \\
$\begin{array}{c}\text { Bank } \\
\text { Account } \\
\text { Mobile }\end{array}$ & -0.15 & 0.09 & -1.58 & 0.12 \\
\hline$*$ Statistically significant at 95\% confidence level. & -3.2 & $0.003^{*}$ \\
\hline
\end{tabular}

The Table I Shows the results of Ordinary Least Square (OLS) regression analysis. Coefficient in the table is like Pearson correlation coefficient. The negative sign indicates inverse relationship. Literacy of women has shown a negative correlation with infant mortality rate. The areas with lower literacy rate have shown higher infant mortality. But the relationship is not statistically significant which might have happened due to small sample size. In another study in Kashmir Valley, linear regression model showed similar results [8].

World Health Organization recommends the presence of trained birth attendant at the time of delivery to ensure prevention, detection, and management of any complication [9]. In the present study, institutional delivery has shown negative correlation with infant mortality. The states with higher percentage of women delivering in an institution, have shown statistically significant lower infant mortality rates (coefficient $=-0.32, \mathrm{p}=0.01$ ). It indicates that with every 1 unit increase in percentage of institutional delivery, there is a 0.32 unit decrease in infant mortality rate. These findings are in tune with another study in southern and central India which showed similar results [10]. Pardhan Mantri Jan Dhan Yojna, a financial inclusion program, was started in 2014 which envisages universal access to banking facility [11]. How far this facility has led to improvement in maternal and child health has not been much explored in Punjab. In the present study, it was observed that the states with higher percentage of women having their personal bank account have shown lower infant mortality rate. Singh A et al has shown that women having bank account are more likely to get minimum four antenatal checkups and delivering in an institution leading to improvement in child survival [12]. This might had led to the improvement child health and hence low infant mortality rate.

The states with higher percentage of women owning a mobile phone have also shown lower infant mortality rate in the present study and the results are statistically significant at $95 \%$ confidence level. The availability of mobile phone might have empowered the women to get access to acceptable and affordable alternative approaches for the better care of their child [13]. Participation in decision and owning a land or house were not found to be statistically significant factors.

Regression diagnostics showed the $\mathrm{R}$ square to be 0.65 . The $\mathrm{R}$ square explains overall performance of the model. The current model thus explains $65 \%$ of infant mortality rate. Jarque Bera test was not statistically significant at $95 \%$ confidence level $(\mathrm{p}=0.7)$ depicting that the results are not biased. Also, the tests for heteroskedasticity i.e., BreuschPagan test $(p=0.15)$ and Koenker-Bassett test $(p=0.07)$ were not statistically significant showing homogenous distribution of attributes.

To adjust spatial dependence, spatial lag and error models were applied in GeoDa. The fitted models were compared by R square value (Table II). The perusal of Table II depicts that spatial models also show similar exploratory variables affecting infant mortality rates, but results are more significant. Out of three models i.e., classical OLS regression model, spatial lag model and spatial error model, the $\mathrm{R}$ square is highest in spatial lag model. It also shows lower log likelihood (lower the better) and higher AIC (Higher is better).

\begin{tabular}{ccccccc} 
TABLE II. THE COMPARISON OF CLASSICAL OLS, SPATIAL LAG AND SPATIAL ERROR REGRESSION MODELS \\
\hline \multirow{2}{*}{ Covariate } & \multicolumn{2}{c}{ Classical Model } & \multicolumn{2}{c}{ Spatial Lag Model } & \multicolumn{2}{c}{ Spatial Error Model } \\
\cline { 2 - 7 } & Estimate & $\mathrm{p}$ value & Estimate & $\mathrm{p}$ value & Estimate & $\mathrm{p}$ value \\
\hline Intercept & 70.6 & 0.008 & 61.58 & 0.008 & 71.6 & 0.001 \\
Institutional Delivery & -0.32 & 0.01 & -0.27 & 0.009 & -0.33 & 0.001 \\
Women Literacy & -0.11 & 0.58 & -0.10 & 0.57 & -0.10 & 0.57 \\
Decision & -0.13 & 0.67 & -0.13 & 0.62 & -0.13 & 0.62 \\
Own land & 0.15 & 0.12 & 0.17 & 0.05 & 0.14 & 0.09 \\
Bank Account & -0.34 & 0.02 & -0.35 & 0.006 & -0.36 & 0.005 \\
Mobile & -0.49 & 0.002 & -0.47 & 0.0003 & -0.5 & 0.0002 \\
$\mathrm{R}^{2}$ & \multicolumn{2}{c}{0.65} & & 0.66 & & 0.65 \\
\hline
\end{tabular}




\section{CONCLUSION}

Institutional delivery, owning a bank account and availability of personal mobile phone were found to be significant factors affecting infant mortality rate in India. Spatial lag regression model was the best fit model to predict infant mortality rate. The northern and eastern states were predicted to have highest infant mortality rate. Mapping of predicted infant mortality rate in various states can help us to identify high risk areas. The information thus obtained can be used to improve the national programmes in terms of allocation of limited resources. Further study at individual level may be planned in these states to find out the risk factors.

\section{LIMITATIONS}

The measures of exposure are based on the average value in population. Therefore, the results cannot applied to individual level. Inability to control for confounding is another limitation of the study. Modifiable area unit problem may affect the results as well.

\section{REFERENCES}

[1] S. Yadavar, and S. Raman. Here's why India has one of the highes rates of infant mortality in the world. The Wire. Jan 10, 2020. Available: https://thewire.in/health/infant-deaths-india.

[2] H. Plecher. Infant mortality rate in India 2019. Statista. Oct 20, 2020 Available:https://www.statista.com/statistics/806931/infant-mortalityin-india/.

[3] United Nation's Children Fund. Levels \& Trends in Child Mortality. 3 UN Plaza, New York, New York, 10017 USA. (2019) Available: http://documents1.worldbank.org/curated/en/105841568905930695/p df/Levels-and-Trends-in-Child-Mortality-Report-2019.pdf.

[4] World Health Organization. Making pregnancy safer: the critical role of the skilled attendant. Geneva: 2004, pp. 01. .Available: https://apps.who.int/iris/bitstream/handle/10665/42955/9241591692.p df;jsessionid=46FD83EA678C 98823641 AEB930C530B9? sequence= 1.

[5] International Institute for population Sciences. National Family Health Survey -4 (2015-16). Deonar, Mumbai, 2017, pp. 507-516 Available: http://rchiips.org/nfhs/NFHS-4Reports/India.pdf.

[6] D. Z. Sui. Tobler's first law of geography: A big idea for small world? Annals of the Association of American Geographers. Vol. 94, no. 2, pp. 269-277, 2004

[7] Silva SL, Fachel JM, Kato SK, Bassanesi SL. Patterns of variation in infant mortality rate in Rio Grande Sul State, Brazil: comparison of empirical Bayesian and family Bayesian approaches. Cad. Saúde Pública, Rio de Janeiro, vol. 27, no. 7, pp.1423-1432, 2011.

[8] Batool N, Shah SA, Dar SN et al. Impact of female literacy on infant mortality and maternal mortality in Kashmir valley: a district level analysis. GeoJournal, vol. 85, pp. 1545-1551, 2020. Available: https://doi.org/10.1007/s10708-019-10041-1.

[9] World Health Organization. The global health observatory. Global health data platform/GHO/Indicator metadata registry list. https://www.who.int/data/gho/indicator-metadata-registry/imrdetails/institutional-birth.

[10] Goudar SS, Goco N, Somannavar MS, Vernekar SS, Mallapur AA et al. Institutional deliveries and perinatal and neonatal mortality in Southern and Central India. Repro Health. [Online]. Vol. 12, no. 2, pp. 1-9, 2015. S13 doi: 10.1186/1742-4755-12-S2-S13.

[11] Government of India. Pardhan Mantry Jan Dhan Yojna. Available: https://pmjdy.gov.in/scheme.

[12] Singh A, Kumar K, McDougal L, Silverman JG, Atmavilas Y, Gupta $\mathrm{R}$, Raj A. Does owning a bank account improve reproductive and maternal health services utilization and behavior in India? Evidence from the National Family Health Survey 2015-16 SSM Popul Health. [Online]. vol. 7: 100396, April 2019.
[13] Musiimenta A, Tumuhimbise W, Mugyenyi G, Katusiime J, Atukunda EC, Pinkwart N. Mobile phone-based Multimedia Application Could improve Maternal Health in Rural Southwestern Uganda: Mixed Methods Study. Online j Public Health Inform. Vol. 12, no. 1, 2020. doi: 10.5210/ojphi.v12i1.10557. 